Article

\title{
The G1000 Firework Dialogue as a Social Learning System: A Community of Practice Approach
}

\author{
Franziska Eckardt * and Paul Benneworth \\ University of Twente, Center for Higher Education Policy Studies, Drienerlolaan 5, 7522 NB Enschede, \\ Overijssel, The Netherlands; f.eckardt@utwente.nl (F.E.); p.benneworth@utwente.nl (P.B.) \\ * Correspondence: f.eckardt@utwente.nl; Tel.: +31-(0)53-489-6303
}

Received: 25 June 2018; Accepted: 2 August 2018; Published: 5 August 2018

\begin{abstract}
New public governance studies have increasingly sought to highlight the importance of citizen engagement in local decision-making processes as a way to identify suitable approaches to matters of public concern. There is a particular absence of good theoretical development building upon empirical work exploring citizen participatory processes as potential sites for social learning. In this paper, we asked the overall research question of the extent to which a new citizen participation process can be designed as a social learning system to facilitate the integration of citizen types of interests and knowledge in local decision-making. To answer this question, the study's results provided deeper insights into the internal social learning dynamics within one particular deliberately designed collective local decision-making process, the G1000 firework dialogue in Enschede, The Netherlands. Using Wenger's concept of "communities of practice" (CoP) as a baseline for analysis, the results of this study indicated that the G1000 firework dialogue process encouraged the creation of activities that may be considered to correspond to the different structural dimensions of $\mathrm{CoP}$ and that new design-based models of citizen participation would benefit from adopting a more explicit incorporation of and orientation towards social learning practices and theories. Consequently, we argue that local governance should invest more in citizen participation processes that encourage and enable learning among different societal stakeholders with different interests through constructive dialogues over political matters.
\end{abstract}

Keywords: social learning systems; communities of practice; common ground formation; participatory decision-making processes; participatory local governance; G1000

\section{Introduction}

Since the early 20th century, a so-called "deliberative turn" has taken place in democratic theory (Manin 1987; Bohman 1997; Dryzek 2000) with communication and reflection increasingly becoming the focus of the democratic discourse (Habermas 1996). It is therefore supposed that information exchange between various informed social actors might improve the quality of decision-making in increasingly complex matters of public concern (Neyer 2006). This turn was marked by a notion that individuals may be regarded as competent and rational actors/agents, and should more closely be involved in day-to-day politics, as they can reflect on their preferences during these open dialogues (Chambers 2003; Ganuza and Francés 2012). More recently, new public governance studies increasingly began highlighting the importance of citizen involvement in local decision-making processes to generate through social interactions suitable approaches to matters of public concern (Galli et al. 2014; Head and Alford 2015; Lovan et al. 2017). Previous studies indicated that citizen participation processes designed using deliberation-centric approaches could lead to more informed, involved, and educated citizens (Luskin et al. 2002; Gutmann and Thompson 2009; Arendt 2010; Grönlund et al. 2010). This belief is also reflected in an increasing number of participatory governance models (e.g., collaborative 
decision-making process, co-producing activities) developed to provide new channels for citizen engagement in local decision-making (Hendriks and Michels 2011; Smith 2009).

However, research shows that the involvement of citizens in the dialogue about and decision-making over local political issues is not always a straightforward process (Watson 2014). Watson (2014) contends that consensus-driven new governance agreements may frequently be characterised by antagonism (e.g., between state actors and citizens) as well as conflicts of interest and knowledge between different participants (e.g., non-experts vs experts) (Innes and Booher 2004; Watson 2014). This conflict may disrupt the deliberative mechanisms by which these new governance models create benefits for citizens, and are a feature rather than side-effect of these models, reflecting often hidden wider societal tensions and inequalities (Innes and Booher 2010; Ansell 2011). In addition, a lack of representation and decision-making authority in new participatory governance agreements may hamper the influence exerted by citizens' knowledge within these collective decision-making processes (Arnstein 1969; Fischer 2000; Smith and McDonough 2001; Moulaert et al. 2010).

As part of a wider so-called "turn to practice" (Soler et al. 2014), social learning theories have emerged to deal with situations where useful and usable knowledge is created through interactions between participants in social learning communities in the absence of a common ground. According to these studies, social learning processes might emerge within a participatory process when different societal actors (individuals or groups) with various interests and knowledge learn from each other through constructive dialogue. According to Innes and Booher (2010), there is a need to account for the fact that citizens might participate despite not necessarily agreeing with the implicit proposals underlying the participatory process's rationale (pp. 172-73). Under such conditions, there is an emerging recognition that social learning theories provide a means to understand how community engagement features in new kinds of participatory governance processes (cf. Pretty 1995; Muro and Jeffrey 2006; Woodhill 2010).

Despite this recognition, the uptake of social learning theories within new public governance studies has been relatively limited (with a number of exceptions, e.g., Innes and Booher 2010; Ansell 2011). There is a particular absence of good theoretical development building upon empirical work exploring citizen participatory processes as potential sites for social learning (Muro and Jeffrey 2006; Reed 2008). There has likewise been little reflection on whether social-learning-based citizen participation processes might have value in new governance agreements that seek to incorporate citizen knowledge in their outcomes. Consequently, this study aims to address this lacuna by asking the following research question: To what extent can a new citizen participation process be designed as a social learning system to facilitate the integration of citizen types of interests and knowledge in local decision-making?

To answer this, we first set out the design requirements for a citizen participation process as a social learning system in Section 2, drawing explicitly on Wenger's "Community of Practice" theory. In Section 3, we present our research approach to consider one specific citizen participatory process, the G1000 in Enschede. In Section 4, we explore the extent to which the activities it promoted led to social learning from a "Community of Practice" perspective. Finally, we reflect in Section 5 upon whether new citizen participation processes could benefit from more focus on these social learning processes by providing an answer to the overall research question of this paper.

\section{Design Requirements for a Citizen Participation Process as a Social Learning System}

Social learning theories address the "processes and structures necessary to involve a heterogeneous set of [societal actors (individuals, or groups)] in analysing and making decisions about complex, multifaceted and value-laden problem situations" (Woodhill 2010, p. 62). Social learning dynamics and processes are constitutive of systems through the interrelated interactions between different (societal) actors involved, giving those learning processes an interactive-multidimensional locus (as opposed to linear-unidimensional). Wenger (2011) argued that a site of a social learning system, therefore, could be regarded as an assembly of single interrelated subunits, something he 
termed "communities of practice" (hereafter referred to as CoP). Wenger (2011) defined a CoP as a "group of people who share a concern or a passion for something they do and learn how to do it better as they interact regularly" (p. 1). A CoP can be viewed as a "small" social learning system where systemic relationships are embedded within three kinds of community characteristic (see Figure 1 below; Wenger 1998). These characteristics emerge from the social learning embedded within the interactions and these, in turn, produce a systemic output (the "knowledge in action", Amin and Roberts 2008). The first of these characteristics is joint enterprise, which refers to a common purpose that binds community members together and provides them with (a) unified goal(s) to take action. More specifically, this includes the development of a shared sense of responsibility among community members to share information with each other to achieve the joint goal(s) of their community. Second, mutual engagement provides the basis for relationship building within a community. It involves regular interaction among community members who negotiate the meaning of a group's culture and its practices. Third, shared repertoire includes the continual development of routines and common ways of working that become embedded in the CoP. This also involves shared practices and "rituals" which shape individuals through their participation and serve to define their CoP positionality.

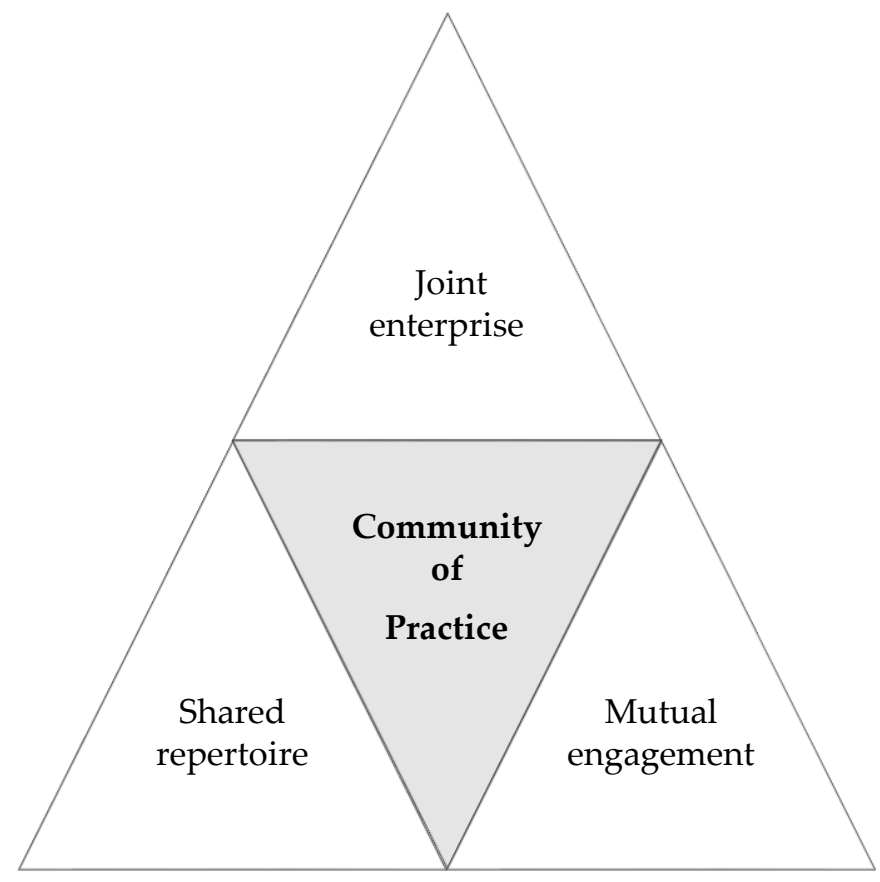

Figure 1. Three dimensions of a community of practice (CoP). Source: Based on Wenger (1998).

Although these characteristics were developed in the context of an insurance claims processing office, the concept has been expanded to a wide range of fields where heterogeneous actors with different value systems and knowledge come together and interact as part of attempts to use each other's knowledge (Gertner et al. 2011; Maxwell and Benneworth 2018). According to Ison (2012), participatory dialogue within the field of urban panning "is a process that does not seek consensus, but provides an environment for learning, to think together" (see Woodhill 2010, p. 81). In these constructive dialogues, problems are analysed and shared understanding is built of a wider situation as well as a common purpose for joint action. We contend that citizen participation processes founded on dialogue, even where there is epistemological divergence (common ground) between initiators and participants, could potentially represent sites of social learning. In such situations, citizen participation processes may mobilise activities stimulating these three characteristics. These activities, therefore, would indicate the presence of social learning processes, from which can be inferred that the dialogue 
has been constructive, and hence represent a first step in citizen knowledge being incorporated into local decision-making processes.

If participatory dialogues represent social learning communities, then these three $\mathrm{CoP}$ dimensions may also be present in the context of these citizen participatory processes, and this provides the basis for our conceptual framework (see Table 1 below). Joint enterprise would involve a group of citizens who would come together from very different societal segments and identify a common theme of interest to work together which was also supported by local policy-makers; they would individually identify that addressing the issue collectively would advance their individual interests, thereby underpinning their commitment to and participation in the reflective learning process. Mutual engagement would be provided by forums in which participants regularly came into contact with each other to discuss and to address a set of problems and in which progress was made to collectively agreed solutions to these problems within these teams. Shared repertoire would be manifested in terms of a "localisation" of externally developed methodologies through the course of implementation efforts, visible in the creation of new kinds of vocabulary, meeting spaces, and behavioural norms.

Table 1. Conceptual framework.

\begin{tabular}{cll}
\hline Characteristic & Indicators & \multicolumn{1}{c}{ Question } \\
\hline Joint enterprise & $\begin{array}{l}\text { Common goal; common } \\
\text { ground formation; joint } \\
\text { action; task delegation; } \\
\text { learning energy }\end{array}$ & $\begin{array}{l}\text { Do group members share a common purpose, which } \\
\text { provides them with a joint goal for (joint) actions? Do } \\
\text { group members develop a shared sense of } \\
\text { responsibility to share information? }\end{array}$ \\
$\begin{array}{c}\text { Mutual } \\
\text { engagement }\end{array}$ & $\begin{array}{l}\text { Relationship building; } \\
\text { information flow; } \\
\text { nature of conversations; } \\
\text { identity building }\end{array}$ & $\begin{array}{l}\text { What events and interactions weave the community } \\
\text { and develop trust? Does this result in an ability to } \\
\text { negotiate the meaning of a group's culture and its } \\
\text { practices? }\end{array}$ \\
\hline $\begin{array}{c}\text { Shared } \\
\text { repertoire }\end{array}$ & $\begin{array}{l}\text { Development of routines and } \\
\text { common ways of working }\end{array}$ & $\begin{array}{l}\text { To what extent have shared experience, language, } \\
\text { artefacts, histories, and methods accumulated over } \\
\text { time and with what potential for future interactions } \\
\text { and new means? }\end{array}$ \\
\hline
\end{tabular}

Source: Based on Wenger (1998).

\section{Background to the Case Study and its Methodology}

\subsection{Case Study Methodology and Ethical Considerations}

In this paper, we ask whether a citizen participation process can facilitate social learning processes that lead to constructive dialogue better incorporating citizens' interests into the overall participatory outcomes. The relative novelty of the application of our approach to public administration warrants an exploratory methodology. We here seek to create an in-depth understanding of whether these social learning processes are evident in citizen participatory activities and the potential dynamics of those social learning processes in these governance contexts. For this purpose, we adopt a critical realist position in which we seek to identify behavioural patterns and regularities and relate them back to our conceptual framework, thereby deepening our understanding of the dynamics of the processes proposed in this framework. Yin (2009) argues that a case study method provides a useful tool to analyse and understand complex social phenomena within their contexts, permitting freedom to understand empirical phenomena before relating them back to conceptual frameworks. We therefore choose an in-depth empirical case study of a single attempt to use a designed citizen participation process to improve the quality of that citizen input.

The study uses an ethnographic participation observation approach allowing the examination of a specific case in the context of its social context (environment and relationships) including the full richness of its formal and informal settings and relations. A mixed-methods approach was 
used to obtain better insights in the formal as well as informal events and relationships during the participation process as well as to reduce non-sampling errors. This article focusses on one particular citizen participation process, namely the "G1000 firework dialogue" (Dutch: "Stadsdialoog vuurwerk-G1000Enschede") initiative (see Section 3.3).

Data collection involved three qualitative data collection methods: (1) qualitative semi-structured interviewing, (2) survey questionnaire, and (3) the collection of observational data (see Figure 2). Interviews were undertaken with G1000 participants identified during formal and informal process-related events and activities; these interviews were recorded (respecting confidentiality agreements) and transcribed. Additional qualitative data were collected via an online survey sent to participants at three moments, namely, (a) immediately prior to the "citizens' summit" $(n=125)$; (b) directly following the "citizens' summit" $(n=65)$; and (c) following the "citizens' decision" $(n=41)$. The interview transcripts and open-ended survey questions were used to elucidate the underlying meaning of the citizens' narrative statements.

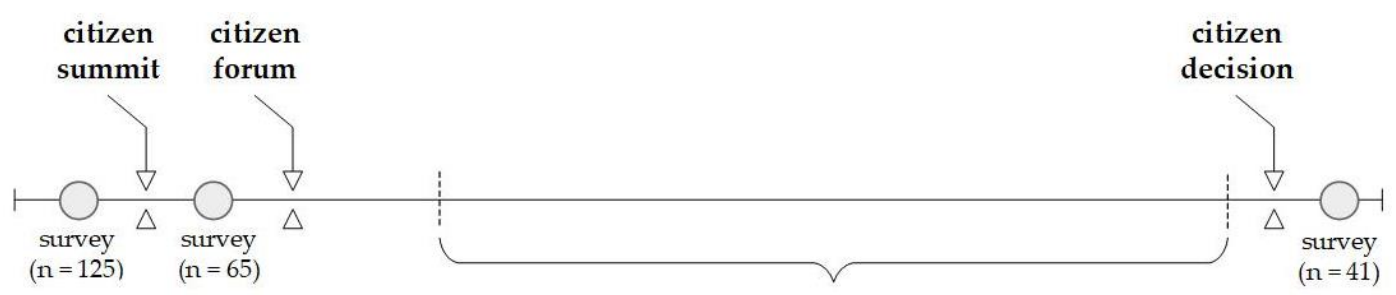

semi-structured interviews $(\mathrm{n}=16)$

Figure 2. Three sources for qualitative data collection process.

Both data sources were analysed within Atlas.ti using a coding technique ${ }^{1}$ (see Table A1 for the codebook, Appendix A; Babbie 2015). Observational data were recorded in the form of the field researcher's "research journal" to keep track of the day-to-day events as well as (un-)exceptional occurrences during the participation process. Study results were shared with research participants who were offered the chance to ask questions and provide feedback on our findings. The fieldwork was undertaken within our faculty's ethical frameworks for social science researchers, and the data here is presented in anonymised and confidential form to conform to these ethical obligations.

\subsection{Background to the G1000 Initiative(s) in Belgium and The Netherlands}

During the last couple of years, various "micro-deliberative" techniques have been developed (Goodin 2008). These micro-deliberative innovations, also referred to as mini-publics, often differ in their design (e.g., through the use of consultation procedures, random selection technique, or e-participation tools), but have in common that they focus on small-group deliberation (Goodin 2008). The G1000 initiative can be considered as one example of a new type of mini-public (the most frequent forms in this genre include consensus conferences, deliberative opinion polls, citizens' juries, 21st century town meetings).

Originally, the roots of the G1000 initiative lie in an experiment that took place in Brussels on 11 November 2011. In contrast to previous citizen participation initiatives led by various levels of government or scientific institutions, the G1000 in Belgium was both initiated and organised by a citizen initiative (Caluwaerts and Reuchamps 2012). The initiators aimed to provide ordinary citizens with the opportunity to discuss pressing societal problems and solutions regarding the future of Belgium. It was developed as a three-stage process including three different types of participatory practices: (1) public consultation (large-scale online consultation), (2) citizens' summit (large-scale deliberation),

1 Inter-coder reliability of 96 percent. 
and (3) citizens' panel (in-depth deliberation) (Caluwaerts and Reuchamps 2012). Its large scale-with more than 6000 citizens participating in the first stage of the process-and a combination of both consultative (e.g., public agenda setting) and deliberative participatory practices, saw the experiment receiving great attention from national and international media, politicians, and practitioners as a new "democratic innovation"2 (Caluwaerts and Reuchamps 2012).

"G1000" as a new citizen participation technique came to the Netherlands in 2014 via the citizen initiative "Platform G1000", located in the Dutch city of Amersfoort. Similar to its Belgian predecessor, the PlatformG1000 aimed to provide citizens with a platform through which they can exchange knowledge and make decisions about matters affecting them. The PlatformG1000 was supported by the Dutch Ministry of the Interior and several private funding partners and since 2014 organized 16 G1000 initiatives across the Netherlands.

During all its G1000 events, the PlatformG1000 makes use of six overall principles: (1) no agenda, (2) open dialogue, (3) random sampling, (4) whole system, (5) transparency, and (6) safety. The first principle seeks to assure that citizens get the opportunity to discuss the things that matter to them, and are provided with a say in setting and shaping the agenda for the meetings in the overall process. The second principle is related to the agenda-setting power at a G1000 event, and aims to direct the processes towards constructive compromise arrangements rather than predetermining which interest positions can dominate decision-making. The third principle is of inviting a random sample of the local community to initial meetings to provide a better reflection of what matters to residents. The fourth principle is that the citizens' summit should be a reflection of the local community, implying that all main stakeholders (local politicians, entrepreneurs, professionals, "free thinkers", and inhabitants) are invited to the open dialogue. The fifth principle is of transparency and openness about how ideas and outcomes are generated at G1000 events. The final principle is ensuring participants' safety throughout the whole process, following predetermined programs ensuring open conversations without physical conflicts.

\subsection{The G1000 Firework Dialogue in Enschede}

In its earlier experiments, the PlatformG1000 was facing the problem of turning the results of a G1000 event (citizens' ideas and proposals) into action, because as a voluntary initiative it did not have a means to compel local authorities to make use of its revealed knowledge and ideas. PlatformG1000's primary goal in Enschede was to foster democratic change by providing ordinary citizens with a stronger voice in local politics for the first time and to ensure that they became implemented by the local government. The approach taken involved integrating and implementing two kinds of tools, innovative micro-deliberative practices (e-participation tools) with direct forms of participatory practices (citizens' decision). The G1000 firework dialogue was initiated by the newly appointed mayor in Enschede in early 2017 as a response to a series of firework-related problems (e.g., firework noise pollution problem, high repair costs for collateral damage, illegal firework use), which occurred on New Year's Eve 2016/17.

This initiative ran from 10 June 2017 until 11 November 2017 in Enschede, a city located in the Dutch Twente region (see Figure 3). Although fireworks had been a practical problem in Enschede for a number of years around New Year's Eve, it was a highly sensitive issue locally because of a disaster in 2000 where a local inner-city fireworks factory had exploded killing 23 people, still commemorated annually. To talk about the (re-)occurring problems related to fireworks on New Year's Eve, thereby addressing the sensitive issue in a proper way, the mayor wanted to engage the "whole city" in a citywide dialogue to generate binding agreement(s) on firework use in Enschede to ensure a more pleasant coexistence on New Years' Eves in the future. The mayor hired PlatformG1000 to design and

2 For example, the G1000 was nominated for the "Prijs voor de Democratie" (in Engl. "Award for Democracy") in 2011. 
organise a citywide firework dialogue in Enschede in collaboration with a working group of local authority officers from Enschede municipality ("Regiegroep stadsdialoog vuurwerk").

The G1000 firework dialogue in Enschede involved an ongoing participation process, punctuated by formal events and activities leading up to a final citizens' decision. This decision was subsequently adopted by the City Council, which the mayor had promised to participants conditional upon them producing an implementable decision. The participation process is shown in Figure 4 below, and involved three main formal events: a citizens' summit (in Dutch: "burgercafé"), a citizens' forum (in Dutch: "burgerforum"), and a citizens' decision (in Dutch: "burgerbesluit"3).

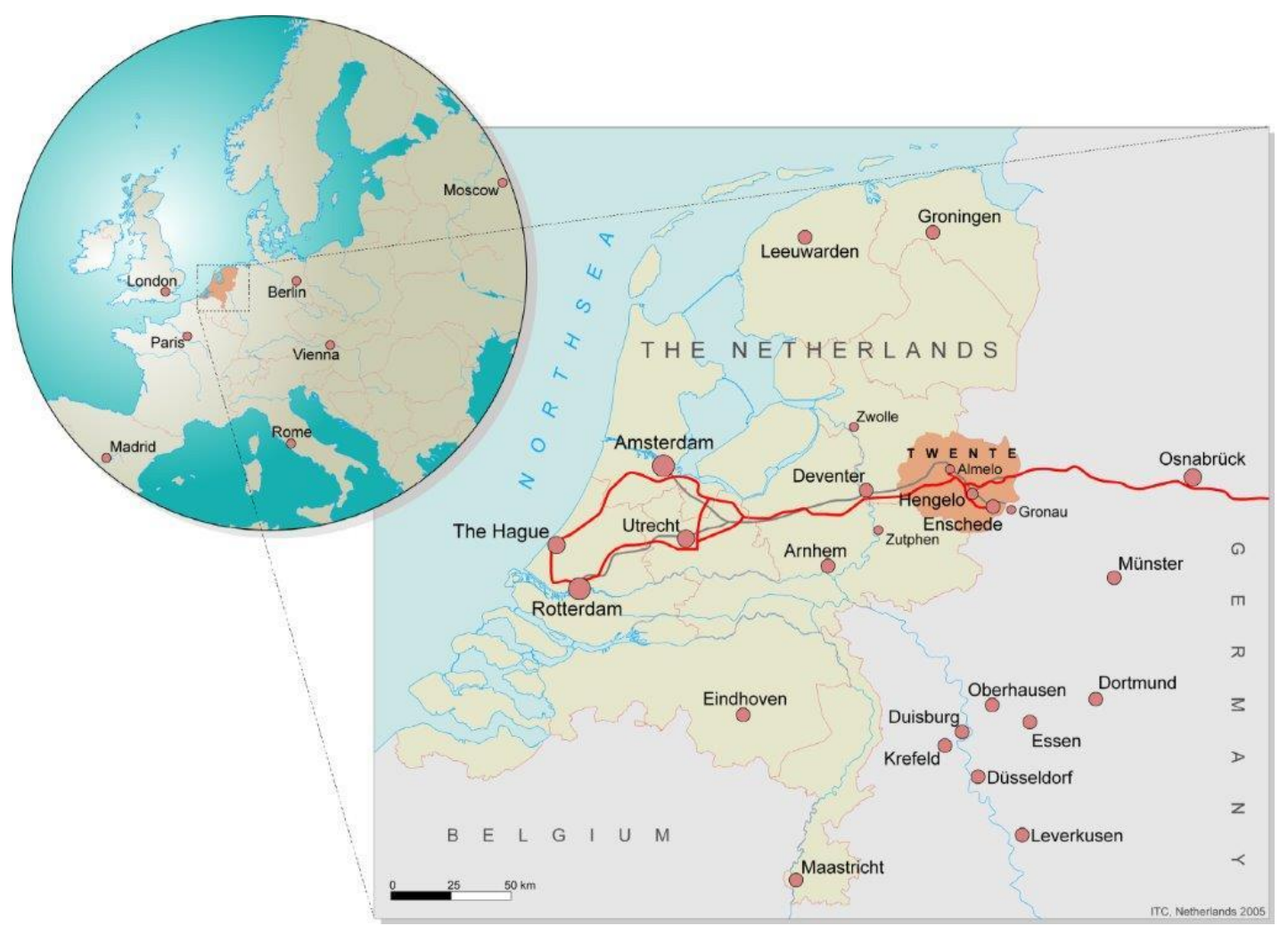

Figure 3. The Twente region. Source: : ITC, 2005 (Courtesy of Faculty ITC, University of Twente)

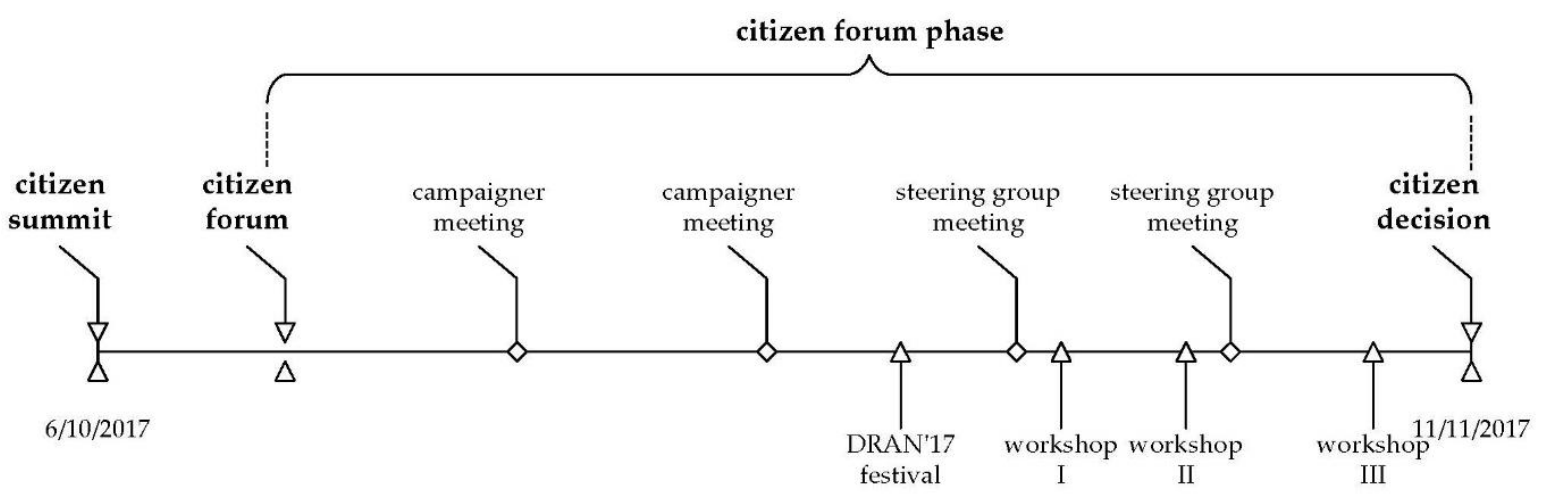

Figure 4. Formal structure of the participation process.

3 The term closing meeting (in Dutch: "slotbijeenkomst") was also often interchangeably used when referring to the final event. For consistency reasons, the authors, however, have decided to adopt the Platform G1000 terminology. 
The citizens' summit was held on 10 June 2017 as the launch event for the dialogue, with a random sample of 10,000 residents invited alongside targeted invitations to local stakeholders (described by organisers as professionals, civil servants, local politicians, and "free thinkers"). A total of 311 participants attended the citizens' summit. Participants were distributed across several tables ${ }^{4}$ to hold open dialogues in several rounds on issues related to firework use in Enschede. The table discussions were facilitated by a group of trained table hosts who had been briefed on general G1000 principles, practical arrangements, and the software used for the day (a presentation package as well as a proprietary dialogue-voting application). Participants developed proposals during the day that were then presented back to the plenary session in the afternoon and voted upon.

The citizens' forum took place at Enschede Town Hall on 1 July 2017, involving participants who had participated in the citizens' summit. During the citizens' forum, the various proposals made at the citizens' summit were grouped into eight thematic areas, namely, (1) law enforcement, (2) schools, (3) awareness raising, (4) development of a mobile app, (5) firework show, (6) firework(-free) zones, (7) upgrading of consumer fireworks, and (8) responsibility. Participants were then invited to register for a working group to elaborate one of those themes into a detailed written proposal to be presented at the citizens' decision in November 2017. These groups worked over the summer to finalise the proposals, with some smaller meetings taking place within the groups; there were three collective workshops to assist them in compiling their reports practically.

The citizens' decision was a final meeting held at the Town Hall on 11 November 2017. In the morning, each working group firstly presented their ideas in front of three panels (citizens, politicians, and professionals) and were subsequently questioned by panellists. The afternoon session, broadcast live on the national political cable channel, involved the 67 citizen participants voting on six proposals, and formally adopted three proposals: awareness raising in schools, city-wide awareness raising, and firework(-free) zones. After the final meeting, the citizens' decision was formally signed by all participants entitled to vote and a group of citizens signed up for a monitoring group in order to follow and get involved in the elaboration and implementation of the citizens' decision. The mayor presented the civil decision to the members of the municipal council and received formal approval from the members for its further elaboration and implementation. Individual aspects of the citizens' decision were implemented for the New Year 2017/18. Together with the monitoring group, the municipality of Enschede was (at the time of writing) working on further plans to implement all aspects of the citizens' decision prior to New Year 2018/19.

\section{Results}

Having presented an overview of the dynamics of the G1000 firework dialogue in Enschede, we now turn to exploring the extent to which these activities can be considered as constituting "a social learning system". We firstly do that by exploring the extent to which it is possible to perceive the three characteristics of CoPs in these activities within the G1000 firework dialogue, namely, developing a sense of joint enterprise, the emergence of mutual engagement, and the development of shared repertoires (Section 4.1). We then discuss factors that hampered and fostered the creation of a CoP, to better reflect on the way that the citizen participation process contributed to effective social learning among participants (Section 4.2).

\subsection{G1000 Firework Dialogue as a Social Learning System?}

\subsubsection{Developing a Sense of a Joint Enterprise}

The multiple dialogue rounds at the citizens' summit event were reported as places where the participants developed both a greater mutual understanding of each other's perspectives as well as

4 The amount of people at each table varied between 4 and 8 people during morning and afternoon sessions. 
a more general sense of community and solidarity. Although some participants indicated that they had expected conversations to be tense and more polarised between supporters and opponents, ${ }^{5}$ participants described the atmosphere in the room as "positive", "relaxing", and "energising". In addition, many participants stated that they found the table discussions instructive, as many people told their personal and often emotional stories about experienced fireworks accidents or the fireworks disaster in Enschede. Concerning the former, one participant, for instance, indicated that the citizens' summit helped to turn a sensitive subject into a subject that can be discussed openly. Related to this, another participant stated the following:

"Yes, everyone contributed in some way to the discussion and we learned a lot from each other [...].

There were also many people at my table who shared personal experiences and from whom you could get life lessons."

(P28: 2017, 18, G1)

With regard to the firework disaster, many older participants used the opportunity to share their emotional experiences with their fellow citizens during the dialogue rounds, which is expressed in the following quote:

"I also liked to hear how those young people view it and why it is so important for them, and why it is so nice for them. But on the other hand I also found it special to hear from the people who are experiencing nuisance, or who are afraid of fireworks, or who have experienced the fireworks disaster."

(P19: 2017, 34, G1)

A number of participants stated that they improved their understanding of other citizens' opinions on the issue, and that had, in turn, affected the reasons why they thought about it that way. One participant summarised his impression of the different dialogue rounds as follows:

"It was a nice way to exchange arguments with others, thereby seeing things from a different perspective. I did not think about some aspects beforehand. It was nice that-with some exceptions ${ }^{6}$ participants equally contributed to the dialogue."

(P27: 2 measurement; 46:46)

Following the citizens' summit, a number of participants stated that they had perceived a sense of togetherness and solidarity, with some participants indicating that their choice of which group to join at the citizens' forum had been determined or at least influenced by a feeling of mutual understanding and attachment with like-minded people developed during conversations at the citizens' summit event.

Moreover, through their participation in one of the working groups, citizens had managed to find ways to accommodate their desire to fulfil their self-interest along with the service of shared interest, at what might be considered as reaching a common ground. Participants related experiencing the working groups as having a more open and informal atmosphere despite the formal rules because participants had managed to internalise the rules and were not continually constrained by the rules. Several of the groups were able to find this common ground relatively early within the process, and those were the groups where participants were willing to aim from the start to develop a proposal that served all group members' interests. In one group, one interviewee noted that those people who were not happy with the decisions taken in his working group either left the participation process or shifted to another working group. Others stated that they had difficulties to agree within their working group,

5 Some interviewees indicated that they thought prior to the citizens' summit event that the topic would attract predominantly supporters and opponents of fireworks.

6 A few interviewees indicated that they felt disturbed by some dialogue partners who either deviated too much from the topic to tell their personal story or took the floor to defend their position on the matter. 
with a few participants noting that they had what had felt like "endless circular discussions", leading one interviewee to argue that he had specifically decided to take a more active leading role within the group to bring more direction to his groups' activities and progress.

\subsubsection{Mutual Engagement and Interaction within Working Groups}

The second characteristic of a CoP indicative of social learning practices is the presence of mutual engagement and interaction, and this became present within the working groups in various ways. Although there was substantive variation in the ways that individuals organised their participation in the G1000 firework dialogue, participants established their own formal as well as informal ways of communication and interaction between working group members (see for an overview Figure 5 below).

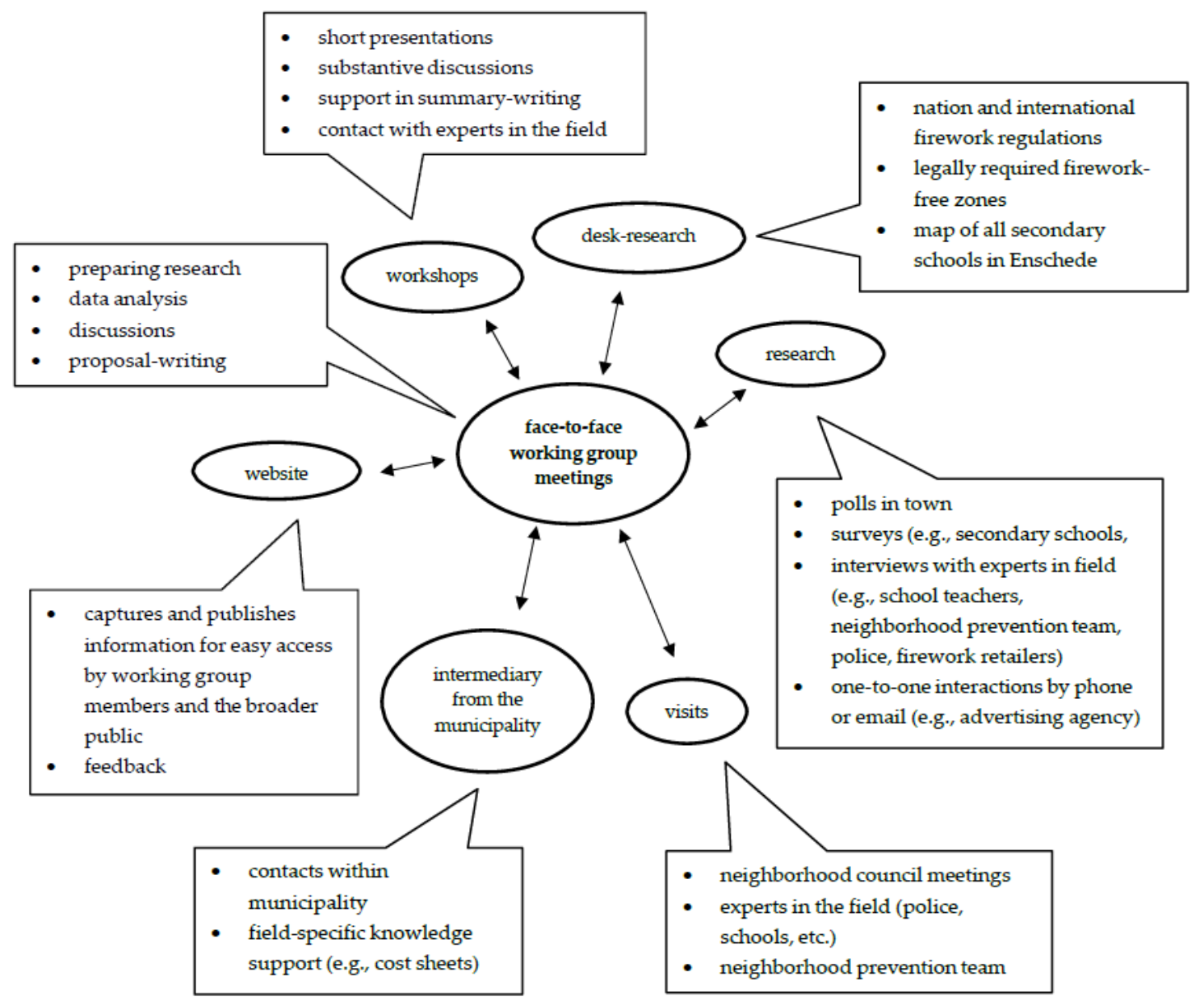

Figure 5. Mutual engagement and interaction within working groups.

During the citizens' forum phase, participants indicated that they met with their working group members in regular face-to-face meetings and used email and WhatsApp for mutual communications. During these formal meetings, participants generated initial ideas on their theme and allocated responsibilities and tasks among working group members. Some participants indicated that they mainly supported their group through listening and providing constructive feedback (based on their expertise and experiences) during formal group meetings. Others indicated that they preferred administrative and internal/external communication functions (e.g., writing minutes of group meetings, organizing formal group meetings). Yet other participants highlighted that they preferred 
research-related ${ }^{7}$ tasks to support internal group discussions and improve the quality of their proposals. A few participants declared themselves to be more interested in creative tasks to support their working groups' advertising efforts (e.g., taking care of the G1000 firework dialogue website, making a draft version for a pitch or poster). An occasional participant indicated that they went to a local democracy festival or tried to promote their working groups' proposals via personal social media channels.

Many participants stated that they perceived the official workshops as important events as part of their working group's efforts to develop a proposal related to their chosen theme. Many interviewees highlighted that during the first two workshops, they discussed substantive issues related to their ideas for the first time. Moreover, participants perceived the first workshop as helpful in the proposal writing process since they got some reflection on their pitched ideas from other working groups. One interviewee indicated that workshops were also useful to make new contacts with other working groups to find new ways of collaboration. Illustratively, some interviewees mentioned that participants of two working groups decided to dissolve their group and to merge with another working group. ${ }^{8}$

During the second workshop, people got the possibility to discuss their ideas and proposals with professionals. One interviewee emphasised that professionals were highly approachable and this provided them with an opportunity to test and get expert feedback on their ideas. Some participants mentioned that the second workshop was helpful to get their ideas down on paper, with civil servants from the municipality's marketing department supporting them in their efforts to prepare short summaries of their plans for the official G1000 firework dialogue website.

Many interviewees stated that they perceived some members of their group as being more dedicated than others in terms of the dedicated efforts made. Likewise, some participants mentioned that they prioritised working group activities above their other commitments ${ }^{9}$; conversely, others indicated a looser connection with the group, merely following group activities (by mail and occasional attendance) dependent on time. Some interviewees reported that most executive functions within the working groups (chair, secretary, moderators, campaigners), were carried out by a small group of more active participants that formed a core group within the working group. There were situations related where this core group were reported as having established informal ways of interaction and communication outside the working group. For example, one participant described this situation as follows:

"I have contact with [person 1] and [person 2] via a separate WhatsApp group because we act a bit like team leaders, uhm ... and with the others, we just have mail contact. If things need to be picked up or worked out, or if we want their opinions, we also mail them. Also, there is one man, I know quite well. I also have a lot of contact with him via WhatsApp and by phone. He is slightly more active than the rest."

(P19: 2017, 34, G1; 203:203)

Conversely, some participants mentioned that these informal ways of communication and interactions within the core group themselves constituted a problem for the wider working group, creating a situation where information and knowledge about the process and incidental events were not always equally provided to all group members.

\subsubsection{Establishing Shared Repertoire}

A final characteristic of CoPs is in the development of a shared repertoire between participants that facilitates the execution of group tasks towards the shared joint enterprise. Throughout the

7 E.g., developing and conducting interviews, surveys, opinion pools among students, experts in the field, and fellow citizens; doing desk-research, or developing first ideas for an app.

8 The app group was dissolved and participants merged with members of the awareness-raising group. The firework show working group dissolved and members merged with the working group on firework(-free) zones.

9 A participant mentioned that he cancelled another meeting for a meeting with his working group. 
participation process, shared repertoires grew in various ways over time. The most common way in which this occurred was that citizens increasingly developed a shared language in their working groups. This became explicit during interviews, since participants predominantly used the "we-form" when talking about events and activities within their working groups (see, for an example, Figure 6). Another thing revealed during interviews was participants mainly describing the purpose of their working group activities and goals using a similar set of vocabulary. When interviewed separately, participants from the "awareness raising" working group each emphasised using a similar line of reasoning the importance of a positively framed local campaign.

There were three other ways shared repertoires could be perceived in this process. First, encouraged by the PlatformG1000, citizens developed various shared written knowledge dossiers in their working groups, such as research documents, formal presentations, and the final proposals. Participants made use, albeit to a limited extent, of an online platform (called "CitizenLab") to initiate interaction among the working group participants and other citizens living in Enschede, where they presented and discussed their ideas. Second, plans for creating future shared artefacts were also developed by some working groups. For example, the working groups "schools" and "firework-free zones" aimed to produce specific firework kits and voluntary fireworks-free stickers for future distribution at local high schools and households. The working group "awareness raising" prepared draft slogans for a local firework campaign in town. Finally, all working groups gained shared experiences throughout the participation process that shaped their mutual interaction and development of enterprises, either through joint activities inside (e.g., workshops) or outside (e.g., field visits) the predetermined participation process structure.

\section{Example}

"We meet regularly in the evening with three people to discuss progress, to discuss how things are going, to plan the next meetings and stuff like that."

(P16: 2017, 13, G1; 99:99)

"We are a small group that is on top of things (asking questions, drawing up surveys). We do communicate all these things back to the working group. Usually, we don't get a response from them, so I still don't know why we are doing this, but $\underline{\text { we }}$ do link everything back to the working group. And there are one or two of them who then respond, and that's just about what it is."

(P18: 2017, 32, G1; 255:263)

"Yes, [I have] a very active role. Let me put it this way, together with two others; we are the driving force, we are very active."

(P19: 2017, 34, G1; 183:183)

"It [contact] is mainly via e-mail. In my workgroup there is a subgroup that sits together a bit more often. That's $X$ and $X$ and ... I've forgot the other name. They have already met several times at $X^{\prime}$ s place with the three of them. This is because they prepared things for the DRAM festival, they went to, for those things actually. And everything that concerns the whole group is mainly communicated by mail."

(P17: 2017, 24, G1; 111:111)

"There was a lot of effort taken by a small number of people. I contributed by listening and commenting if requested."

(P27: 1\&2 measurement; 220:220)

Figure 6. Shared language. 


\subsection{The Overall Effectiveness of the Social Learning Dynamics in the G1000 Firework Dialogue}

\subsubsection{Factors Constraining Participation and Community Building in the G1000 Firework Dialogue}

Throughout the G1000 firework dialogue, three factors became apparent that restrained the effectiveness of participants' engagement in their working groups: first, a perceived lack of process-related transparency; second, the pre-determined structure of the participation process; and, finally, time.

The first issue was a perceived lack of process-related transparency because some people missed a clear and transparent structure being communicated right from the start. Many participants stated that neither the course of actions nor the period of the participation process was clearly communicated at the citizens' summit, which launched the G1000 firework dialogue. Some groups related experiencing substantive internal pressure on their time planning caused by unforeseen activities or events. Some groups also noted that both the number of activities as well as the acceleration of the process towards their end negatively influenced their motivation to participate. Some participants mentioned adopting a "wait-and-see" attitude due to initially feeling overwhelmed because of a perceived lack of process-related information. A few participants indicated feeling deceived by organisers because their contributions were not immediately evident. Conversely, many (of the remaining) participants indicated that process-related instructions became more evident towards the end of the process. ${ }^{10}$

The second set of constraints noted by participants was feeling held back by the participation process's rigid predetermined structure, preferring a more flexible, less predictable process structure. One participant stated that that the rigid process structure had hampered him from actively involving a group of young people in the participation process ${ }^{11}$. Another participant argued that too much structure risked destroying people's creativity as well as their sense of ownership for their group activities and the participation process in general. Indeed, one interviewee indicated that he had left the participation process explicitly since the rigid predetermined structure reduced his motivation to think creatively and attempt experiments. Some participants stated that they had also expected more assistance from the municipality (e.g., providing budget and expert knowledge support), and resented slightly that they (as volunteers) were not more actively supported at the start of the citizens' forum phase by the municipality in developing their solution.

The final issue constraining participation was that it was felt to be extremely time-consuming, and for some participants, its demands ultimately proved to be too time-consuming. At the end of the dialogue, a substantial number of participants stated that they had initially underestimated the time the participation process would cost them. Participants mentioned that they were surprised by the number of activities they had to execute in their working groups during the early phase of the citizens' forum. Some participants felt constrained by an impression that their working group was "obliged" to meet some predetermined milestones in an arbitrary timeframe (in this case, consulting with neighbourhood councils, attending a democracy festival, holding opinion polls in town). Some interviewees indicated that they started to perceive a number of these mandatory activities as burdensome, with some interviewees spending more than five hours per week on working group activities and related events. A few interviewees questioned why they were not being compensated (financially or in another way) for the considerable time they were expected to invest in the process.

\subsubsection{Perceived Benefits from Participation in G1000 Firework Dialogue}

Following the G1000 firework dialogue, participants provided three overarching arguments that summarised their experiences. First, they individually believed that their participation in the G1000

10 Many participants indicated that after the first workshops the process became more clear.

11 In order to warrant representativeness of the participation process, only people who were randomly selected and received a formal invitation were allowed to participate in the G1000 firework dialogue. 
firework dialogue provided them with a valuable learning experience. A number of participants stated that they liked the process because it provided insights into the municipality's workings, and local politics in general. One participant had stated that through her participation she had come to realise that the finding a comprehensive solution to the problem was not always as simple as it might appear in the first instance. Some participants mentioned that it was relatively easy to contact the G1000 steering group via email or at the formal meetings on occasions when they had questions regarding the participation process, and they perceived the sphere at these meetings as open, with the opportunity to discuss problems arising.

The second set of opinions were expressed that the G1000 firework dialogue appeared to them to represent as a new way to engage citizens in (local) politics. Many participants described the participation process as more democratic and a useful way to involve creative citizens in local decision-making processes of their municipality. Participants indicated that they had been pleased with the formal decision-making at the end of the final meeting, in which the mayor received the three formally approved proposals and affirmed their implementation. A number of participants argued that it was the final formal citizens' decision that was important because of its value in demonstrating that citizens could have real influence on local governance. At the same time, the citizens' opinions of its value remained contingent, in that the value they ascribed to the process was at least partially contingent on the extent to which the citizens' decisions would subsequently be effectively implemented.

Finally, participants suggested that the process had built more understanding for and trust in the local municipality. Some interviewees noted that they perceived a distance between some group members and the local authority officers, notably at the start of the citizens' forum phase. There was some variation in the experiences within the working groups; some participants were simply distrustful of local authority officers in general ${ }^{12}$, while other participants mentioned that they got the impression that municipality participants were not supporting their working groups at the outset of the citizens' forum phase ${ }^{13}$. However, these initial impressions evolved through the life of the process, with many participants relating that by the end of the G1000 firework dialogue they believed that they had effective lines of communication with the municipality. This was underscored when some civil servants were observed to be actively involved in elaborating their working groups' final proposals.

\section{Discussion and Conclusions}

In this paper, we asked the overall research question of the extent to which a new citizen participation process can be designed as a social learning system to facilitate the integration of citizen types of interests and knowledge in local decision-making. In answer to this question, the results provided deeper insights into the internal social learning dynamics within one such activity, Enschede's G1000 firework dialogue, providing the basis for a tentative answer to this question. Wenger's (1998, 2000 , 2011) concept of CoP provides a baseline for analysis, indicating that the G1000 firework dialogue process encouraged the creation of activities that may be considered to correspond to the different structural dimensions of communities of practice. These CoP elements were visible within the different working groups that coalesced in an attempt to create proposals that might address Enschede's controversial firework issue, suggesting that there was social learning present in these activities.

A second element of the findings related to how social learning facilitated the participation process in terms of integrating citizens' interests and knowledge into local decision-making. One clear observation in the study was that despite participants' varying motives for engaging in the G1000 firework dialogue, participants developed a greater understanding for each other's perspectives

12 Some participants were angry with the municipality, since it shared a local newspaper article after the citizens' summit via its official website in which it was wrongly stated that citizens from Enschede had chosen for a firework show.

13 E.g., some working groups faced difficulties with printing and organising rooms during the summer holiday period. 
during multiple stages of the participation processes through open dialogues and exchange of personal experiences about the often sensitive perceived issue. It is perhaps also worth here pointing to the issue of the emotional connection to the issue that created an intergenerational solidarity, from older participants who had experienced the fireworks disaster to younger participants who had experienced the individual cost of firework accidents. Indeed, the shared sense of community and joint enterprise identified in Section 4.1.1 appears to have emerged from the sense of togetherness and solidarity, and the creation of common ground among participants in many of the working groups. Moreover, participants developed their mutual relationships by establishing shared sets of communication as well as documents in their working groups throughout the citizen participation process.

The third element of our question relates to the issue of design, and the extent to which the predesigned structure of the G1000 firework citizen participation process facilitated social learning and integrating citizens' inputs. Our results provide one example that illustrates that design-based citizen participation can support and facilitate the establishment of social learning. This social learning was derived from a "safe" learning environment where participants were provided with opportunities to better understand all dimensions of the question through these predesigned open dialogue and interaction processes. We see here an echo of Woodhill (2010) who pointed out that social learning does not "happen by accident", but requires both conscious design and facilitation (p. 64).

However, the results also highlight that citizen participation in the G1000 firework dialogue was hampered by this rigid design-based process structure, and the relative inflexibility that this brought with it. This lack of flexibility manifested itself in various ways, but generally undermined the citizens' commitment to involvement in the activities, making it more superficial and in some cases even discouraging that participation. This, in turn, has consequences for the deliberate design of future design-based citizen participation processes, or the application of lessons from this case to other situations of more institutionalised forms of citizen participation in local governance. It is vital to establish a good balance between the conscious design and facilitation of participation, while leaving room to citizens for self-organisation, thereby providing them with the opportunity to unfold creativity and their autonomous ways of learning and doing.

Moreover, our research indicates that more balanced design-based models of citizen participation can help to circumvent antagonism and conflicts of interest between citizens and local government actors. Three fundamental design criteria for a deliberately designed participatory process in the future therefore appear to provide transparent and clear coordination of action, and ensure sufficient room for the negotiation of insecurities. The results showed that the process lacked transparency and clarity due to coordination issues, most notably at the beginning of the participation process. Consequently, to improve this difficulty, design-based citizen participation processes should invest more intellectually, financially, and in terms of time from the start. With regard to the latter, the workshop approach enabled citizens and municipality representatives to develop what they reported as trust with other participants. This suggests the necessity and, therefore, transparency of establishing a trustful environment that enables people to develop a sense of place, belonging, and responsibility.

Finally, we would acknowledge that this is a single case study of a complex situation in which we have sought to retrospectively utilise theoretical lenses to see elements of the case that might have hitherto been invisible. We, therefore, remain cautious in our findings and note that our results require further exploration, testing, and validation through more extensive, deductive approaches before they can be fully confirmed. Nevertheless, and mindful of this caveat, we believe in line with our findings that it is legitimate to argue that new design-based models of citizen participation would benefit from more explicitly incorporating social learning practices and theories. Consequently, we argue that local governance should invest more in citizen participation processes that encourage and enable learning among different societal stakeholders with different interests through constructive dialogues over political matters. 
Author Contributions: Conceptualization, F.E., P.B.; Methodology, F.E.; Software, F.E.; Validation, F.E.; Formal Analysis, F.E.; Investigation, F.E.; Resources, F.E.; Data Curation, F.E.; Writing-Original Draft Preparation, F.E., P.B.; Writing-Review \& Editing, F.E., P.B.; Visualization, F.E.; Supervision, P.B.; Project Administration, P.B.; Funding Acquisition, P.B.

Funding: This research was funded by the Netherlands Organization for Scientific Research (NWO), formally under the title 'Whose knowledge matters? Competing and contesting knowledge claims in 21st-century cities' (October 2016-February 2020; reference number: 464-15-114). And the APC was funded by the Knowledge Unlatched initiative.

Acknowledgments: The authors thank Prof. Marcel Boogers for his constructive feedback during the writing process and Babs Ernst for her research support. Furthermore, the authors wish to express their gratitude to all individuals involved for their time, who made the fieldwork possible.

Conflicts of Interest: The authors declare no conflict of interest. The funders had no role in the design of the study; in the collection, analyses, or interpretation of data; in the writing of the manuscript; or in the decision to publish the results.

\section{Appendix A}

Table A1. Codebook.

\begin{tabular}{|c|c|c|}
\hline Code I & Subcode & Code Definition \\
\hline \multirow{5}{*}{$\begin{array}{c}\text { Joint } \\
\text { Enterprise (JE) }\end{array}$} & JE-common_ground_formation & $\begin{array}{l}\text { Refers to the extent members follow the same or } \\
\text { different ways of reasoning. }\end{array}$ \\
\hline & JE-common_goal & Refers to the extent members aim to achieve a joint goal. \\
\hline & JE-action & $\begin{array}{l}\text { Refers to the extent members develop a common } \\
\text { purpose for joint action. }\end{array}$ \\
\hline & JE-level_of_learning_energy & $\begin{array}{l}\text { Refers to the extent members get the opportunities to } \\
\text { negotiate a joint inquiry and important questions. }\end{array}$ \\
\hline & JE-task_delegation & $\begin{array}{l}\text { Refers to the extent members have a common } \\
\text { understanding about who does what. }\end{array}$ \\
\hline Code II & Subcode & Code Definition \\
\hline \multirow{4}{*}{$\begin{array}{c}\text { Shared } \\
\text { Repertoire (SR) }\end{array}$} & SR-experience & \multirow{4}{*}{$\begin{array}{l}\text { Refers to the extent members have accumulated common } \\
\text { resources (experiences, language, methods, and artefacts) } \\
\text { over time that foster potential future interactions. }\end{array}$} \\
\hline & SR-language/jokes & \\
\hline & SR-methods & \\
\hline & SR-artefacts & \\
\hline Code III & Subcode & Code Definition \\
\hline \multirow{7}{*}{$\begin{array}{l}\text { Mutual } \\
\text { Understanding } \\
\quad \text { (MU) }\end{array}$} & MU-nature & $\begin{array}{l}\text { Refers to the way members develop shared ways of } \\
\text { engaging in doing things together. }\end{array}$ \\
\hline & MU-relationships & $\begin{array}{l}\text { Refers to the extent members develop trust and } \\
\text { sustained mutual relationships. }\end{array}$ \\
\hline & MU-information_flow & $\begin{array}{l}\text { Refers to the way in which information is exchanged } \\
\text { among members. }\end{array}$ \\
\hline & MU-nature_of_conversations & $\begin{array}{l}\text { Refers to the way in which members engage directly in } \\
\text { conversations with each other. }\end{array}$ \\
\hline & MU-problem_solving_capacity & $\begin{array}{l}\text { Refers to the extent members are able to raise troubling } \\
\text { issues during the discussion. }\end{array}$ \\
\hline & MU-membership & $\begin{array}{l}\text { Refers to the extent there is an overlap in members' } \\
\text { descriptions of who belongs. }\end{array}$ \\
\hline & MU-personal_contribution & $\begin{array}{l}\text { Refers to the extent members know what they can do } \\
\text { and how they can contribute to the enterprise. }\end{array}$ \\
\hline
\end{tabular}




\section{References}

Amin, Ash, and Joanne Roberts. 2008. Knowing in action: Beyond communities of practice. Research Policy 37: 353-69. [CrossRef]

Ansell, Christopher. 2011. Pragmatist Governance: Re-Imagining Institutions and Democracy. Oxford: University Press.

Arendt, Hannah. 2010. Truth and politics. In Truth: Engagements Across Philosophical Traditions. Edited by José Medina and David Wood. Oxford: Blackwell Publishing, pp. 295-314.

Arnstein, Sherry. 1969. A ladder of citizen participation. Journal of the American Institute of Planners 35: $216-24$. [CrossRef]

Babbie, Earl. 2015. The Practice of Social Research. Boston: Cengage Learning.

Bohman, James. 1997. Deliberative democracy and effective social freedom: Capabilities, resources and opportunities. In Deliberative Democracy. Edited by James Bohman and William Rehg. Cambridge: The MIT Press, pp. 321-48.

Caluwaerts, Didier, and Min Reuchamps. 2012. The G1000: Facts, figures and some lessons from an experience of deliberative democracy in Belgium. In The Malaise of Electoral Democracy and What to Do about. Edited by Philippe Van Parijs. Brussels: Re-Bel, pp. 10-33.

Chambers, Simone. 2003. Deliberative democratic theory. Annual Review of Political Science 6: 307-26. [CrossRef]

Dryzek, John. 2000. Deliberative Democracy and Beyond. New York: Oxford University Press.

Fischer, Frank. 2000. Citizens, Experts, and the Environment: The Politics of Local Knowledge. Durham: Duke University Press.

Galli, Francesca, Gianluca Brunori, Francesco Di Iacovo, and Silvia Innocenti. 2014. Co-producing sustainability: Involving parents and civil society in the governance of school meal services. A case Study from Pisa, Italy. Sustainability 6: 1643-66. [CrossRef]

Ganuza, Ernesto, and Francisco Francés. 2012. The deliberative turn in participation: The problem of inclusion and deliberative opportunities in participatory budgeting. European Political Science Review 4: 283-302. [CrossRef]

Gertner, Drew, Joanne Roberts, and David Charles. 2011. University-industry collaboration: A CoPs approach to KTPs. Journal of Knowledge Management 15: 625-47. [CrossRef]

Goodin, Robert. 2008. Innovating Democracy: Democratic Theory and Practice After the Deliberative Turn. Oxford: OUP.

Grönlund, Kimmo, Setälä Maija, and Kaisa Herne. 2010. Deliberation and civic virtue: Lessons from a citizen deliberation experiment. European Political Science Review 2: 95-117. [CrossRef]

Gutmann, Amy, and Dennis Thompson. 2009. Why Deliberative Democracy? Princeton: Princeton University Press.

Habermas, Jürgen. 1996. Between Facts and Norms: Contributions to a Discourse Theory of Law and Democracy. Cambridge: The MIT Press.

Head, Brian, and John Alford. 2015. Wicked problems: Implications for public policy and management. Administration $\mathcal{E}$ Society 47: 711-39. [CrossRef]

Hendriks, Frank, and Ank Michels. 2011. Democracy transformed? Reforms in Britain and The Netherlands (1990-2010). International Journal of Public Administration 34: 307-17. [CrossRef]

Innes, Judith, and David Booher. 2004. Reframing public participation: Strategies for the 21st Century. Planning Theory E Practice 5: 419-36. [CrossRef]

Innes, Judith, and David Booher. 2010. Planning with Complexity: An Introduction to Collaborative Rationality for Public Policy. London: Routledge.

Ison, Ray. 2012. Traditions of understanding: Language, dialogue and experience. In Social Learning in Environmental Management. Towards a Sustainable Future. Edited by Chris Blackmore. London: Springer, pp. 39-57.

Lovan, Robert, Miachael Murray, and Ron Shaffer. 2017. Participatory Governance: Planning, Conflict Mediation and Public Decision-Making in Civil Society. Abingdon: Routledge.

Luskin, Robert C., James S. Fishkin, and Roger Jowell. 2002. Considered opinions: Deliberative polling in Britain. British Journal of Political Science 32: 455-87. [CrossRef]

Manin, Bernard. 1987. On legitimacy and political deliberation. Political Theory 15: 338-68. [CrossRef]

Maxwell, Kate, and Paul Benneworth. 2018. The construction of new scientific norms for solving Grand Challenges. Palgrave Communications 4: 52. [CrossRef] 
Moulaert, Frank, Erik Swyngedouw, Flavia Martinelli, and Sara Gonzalez. 2010. Can Neighbourhoods Save the City?: Community Development and Social Innovation. Abingdon: Routledge.

Muro, Melanie, and Paul Jeffrey. 2006. Social Learning-A Useful Concept for Participatory Decision-Making Processes? Cranfield: School of Water Sciences, Cranfield University.

Neyer, Jürgen. 2006. The deliberative turn in integration theory. Journal of European Public Policy 13: 779-91. [CrossRef]

Pretty, Jules. 1995. Participatory learning for sustainable agriculture. World Development 23: 1247-63. [CrossRef]

Reed, Mark. 2008. Stakeholder participation for environmental management: A literature review. Biological Conservation 141: 2417-31. [CrossRef]

Soler, Lena, Sjoerd Zwart, Michael Lynch, and Israel-Jost Vincent. 2014. Science after the Practice Turn in the Philosophy, History, and social Studies of Science. Abingdon: Routledge.

Smith, Graham. 2009. Democratic Innovations: Designing Institutions for Citizen Participation. Cambridge: Cambridge University Press.

Smith, Patrick, and Maureen McDonough. 2001. Beyond public participation: Fairness in natural resource decision making. Society \& Natural Resources 14: 239-49. [CrossRef]

Watson, Vanessa. 2014. Co-production and collaboration in planning-The difference. Planning Theory E Practice 15: 62-76. [CrossRef]

Wenger, Etienne. 1998. Communities of Practice: Learning, Meaning, and Identity. Cambridge: Cambridge University Press.

Wenger, Etienne. 2000. Communities of practice and social learning systems: The career of a concept. In Social Learning in Environmental Management. Towards a Sustainable Future. Edited by Chris Blackmore. London: Springer, pp. 179-98.

Wenger, Etienne. 2011. Communities of Practice: A Brief Introduction. Available online: https://scholarsbank. uoregon.edu/xmlui/handle/1794/11736 (accessed on 15 June 2018).

Woodhill, Jim. 2010. Sustainability, social learning and the democratic imperative: Lessons from the Australian Landcare movement. In Social Learning in Environmental Management. Towards a Sustainable Future. Edited by Chris Blackmore. London: Springer, pp. 57-72.

Yin, Robert. 2009. Case Study Research, Design \& Methods. Thousand Oaks: Sage.

(C) 2018 by the authors. Licensee MDPI, Basel, Switzerland. This article is an open access article distributed under the terms and conditions of the Creative Commons Attribution (CC BY) license (http:/ / creativecommons.org/licenses/by/4.0/). 